\title{
EVALUATION OF TESTING METHODS TO DEVELOP TEST REQUIREMENTS FOR A WORKSTATION TABLE SAFETY STANDARD
}

\author{
Kristine Severson \\ A. Benjamin Perlman \\ Michelle Muhlanger \\ Volpe National Transportation Systems Center \\ Cambridge, MA USA
}

\author{
Richard Stringfellow \\ TIAX LLC \\ Lexington, MA USA
}

\section{ABSTRACT}

Investigations of passenger train accidents have revealed serious safety hazards associated with the thin, rigid tops of workstation tables, which are common fixtures aboard rail cars. Thoracic and abdominal injuries caused by occupant impact with workstation tables have been cited as the likely cause of two fatalities during a 2002 accident in Placentia, CA [1]. Additionally, workstation tables have been cited as the cause of injury in reports on accidents in Intercession City, FL [2], and Burbank, CA [3].

Currently there are no regulations or safety standards governing the crashworthiness of tables in passenger trains beyond attachment strength requirements. However, research sponsored by the Federal Railroad Administration (FRA) and in collaboration with the American Public Transportation Association (APTA) Passenger Rail Equipment Safety Standards (PRESS) Construction \& Structural working group is underway to develop a mandatory industry safety standard for tables to ensure that they will be designed to provide a minimum level of safety during a train accident

FRA's Equipment Safety Research Program has already developed and tested a prototype table design to demonstrate the improved occupant protection provided by an energyabsorbing table. The prototype table design was tested using a THOR [4] and an H3RS [5], which are advanced anthropomorphic test devices (ATDs), onboard a $35 \mathrm{mph}$ fullscale train-to-train impact test of rail cars modified to incorporate crash energy management (CEM) [6]. Test results demonstrated that the Injury Assessment Reference Values (IARVs) measured by the instrumented ATDs were within human tolerance levels established by the National Highway Traffic Safety Administration (NHTSA) for automotive crashworthiness for the head, neck, chest, abdomen, and femur.

Having demonstrated the effectiveness of an energyabsorbing table, the next step is developing a performancebased safety standard for tables that ensures a minimum level of crashworthiness. The safety standard would employ the use of

RTDF2010-42032

an $8 \mathrm{G}$ dynamic sled test with instrumented ATDs to evaluate occupant injury and structural integrity of the table, similar to the seat test requirements in APTA-SS-C\&S-016-99 [7], which is the industry safety standard for passenger seats in rail cars. Normally, advanced ATDs like the THOR would be required to measure abdominal and thoracic loads caused by the table impact during the sled test. However, use of these experimental ATDs for table qualification testing is not feasible due to their limited availability. Therefore, alternative test methods must be developed to evaluate the crashworthiness of workstation tables.

This paper evaluates several potential methods to measure table crashworthiness, including quasi-static crush testing, pendulum impact testing, drop tower testing, and sled testing with standard Hybrid III $50^{\text {th }}$ percentile ATDs. The pros and cons of these tests are also described. After evaluating the various testing methods, test conditions for two separate tests are proposed for an industry table standard. A companion paper [8] describes analysis results used to establish performance requirements proposed for evaluating table crashworthiness for the safety standard, in accordance with the test conditions proposed in this paper.

\section{INTRODUCTION}

Traditionally workstation tables have been designed for function and aesthetics. Typical construction may include a plywood table top covered with a laminate surface. Tables are usually fastened to the wall with a bracket and screws, and supported vertically by a table leg near the aisle-side of the table.

These types of tables have been shown to convey concentrated abdominal loads to occupants during train collisions. Accident investigations have also determined that these tables can sometimes detach from the wall and floor mounts under the force of occupant loading, cause a loss of occupant compartmentalization, and even trap an occupant in the facing seat pair.

This work is in part a work of the U.S. Government. ASME disclaims all interest in the U.S. Government's contributions. 
Rail vehicle accidents are investigated jointly by the National Transportation Safety Board (NTSB) and FRA. The main objective of the FRA investigation is to learn how the accident happened and to prevent or minimize the consequences of similar accidents in the future. Accident investigations often lead the FRA to sponsor research aimed at developing strategies to mitigate the consequences of similar accidents.

FRA has established a rail accident forensic team to assist FRA investigators as they examine accidents resulting in fatalities or large numbers of serious injuries. The forensic team analyzes the equipment involved in an accident, interviews passengers, and reviews medical records and autopsy reports.

During FRA's forensic investigation of the passenger train accident in 2002 in Placentia, CA, it was concluded that fatalities and serious abdominal injuries were sustained by several passengers seated at workstation tables. The injuries included bilateral rib fractures, sternum fractures, and spleen and liver lacerations, which are consistent with the concentrated loading from a passenger's torso impacting a thin, rigid table [9].

Having identified workstation tables as an area for crashworthiness improvement, FRA sponsored the development of a prototype table, which was designed and fabricated through a collaborative research contract initiated by the Volpe Center.

The key design criteria required that the table must compartmentalize the occupants and reduce the risk of injury to survivable levels. Compartmentalization was ensured by strengthening the attachments between the table and the car body. Injury risk was reduced by employing energy-absorbing aluminum honeycomb to limit and distribute the force delivered to an occupant's abdomen upon impact with the table during a crash. A schematic of the FRA prototype table is shown in Figure 1.

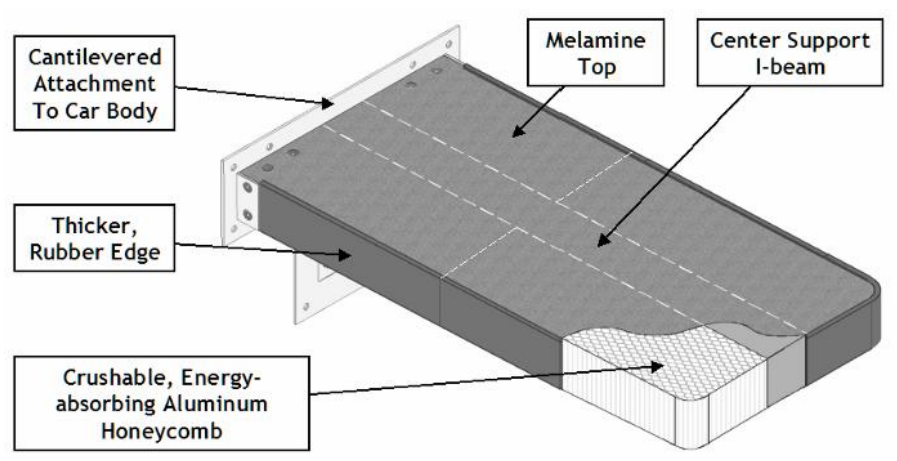

FIGURE 1. SCHEMATIC OF FRA PROTOTYPE TABLE.

The table was tested onboard the leading cab car in the fullscale train-to-train impact test of rail cars incorporating (CEM). A THOR ATD was instrumented to measure tri-axial head and chest accelerations, axial femur loads, shear and axial neck loads, neck flexion/extension moment, bi-lateral threedimensional displacements of the upper and lower rib cage, and linear displacement and acceleration of the upper abdomen. In addition, the table was instrumented to measure acceleration and longitudinal displacement of the aisle-side edge and crush of the wall-side edge impacted by the ATD.

The workstation table experiment demonstrated that the design requirements were met and that the table performed as expected. In other words, the table remained fastened to the wall, and the measured injury criteria were all within the specified maximum thresholds. See Table 1 for a list of injury results. For more detailed information on the design of the FRA prototype table and the test results, see the sources listed in [10] and [6], respectively.

\section{TABLE 1. INJURY RESULTS FOR FRA PROTOTYPE} TABLE.

\begin{tabular}{|l|c|c|}
\hline \multicolumn{1}{|c|}{ Criteria } & $\begin{array}{l}\text { Injury } \\
\text { Threshold }\end{array}$ & $\begin{array}{c}\text { THOR 50th } \\
\text { Percentile male }\end{array}$ \\
\hline $\begin{array}{l}\text { Upper Abdomen } \\
\text { Compression } \\
\text { Ratio }\end{array}$ & $50 \%$ & $26 \%$ \\
\hline $\begin{array}{l}\text { Upper Abdomen } \\
\text { V*C, m/s }\end{array}$ & 1.98 & 1.13 \\
\hline Chest g & 60 & 28.7 \\
\hline HIC15 & 700 & 155 \\
\hline Nij & 1.0 & $0.33(\mathrm{Ntf})$ \\
\hline Neck Tension, lbf & $+937 /-899$ & $+360 /-90$ \\
\hline Femur Load, lbf & 2,250 & $993(\mathrm{~L}) 1,258(\mathrm{R})$ \\
\hline
\end{tabular}

Having demonstrated the effectiveness of a workstation table designed to absorb energy during a collision, the next step is developing an industry standard that can be used to establish a minimum level of crashworthiness for workstation tables. To establish such a standard, test requirements must be developed to measure table crashworthiness, and performance requirements must be established to evaluate table crashworthiness. These two issues are analyzed separately.

A dynamic sled test representing the rail collision environment would be specified using instrumented ATDs to evaluate table performance in terms of occupant compartmentalization and maximum allowable injury criteria. Ideally, a THOR ATD with advanced abdominal instrumentation would be specified, but this is not practical for standard compliance testing because the THOR ATD is not readily available at testing facilities, imposing an unreasonable obstacle.

The rest of this paper focuses on identifying surrogate testing techniques that could be used in lieu a specialized ATD like THOR, but would still provide dependable, repeatable measures of table performance. Potential test techniques that could be used to measure table crashworthiness are examined and recommended in this paper. Performance requirements to evaluate table crashworthiness are examined and recommended 
in a companion paper [8]. The results of these two papers have been used to draft an industry table standard.

\section{INTERIOR CRASHWORTHINESS}

Before describing the test objectives, it is useful to explain interior crashworthiness as it pertains to passenger train accidents. Interior crashworthiness is associated with the capability of interior fixtures and seating arrangements to absorb the kinetic energy of an unrestrained occupant during a train accident. The kinetic energy associated with a moving occupant can be managed by limiting the secondary impact velocity and by designing compliant interior structures that deform under the impact load. The secondary impact velocity, or SIV, refers to the speed, relative to the rail car, with which an occupant's body impacts part of the interior, such as a seat, table, bulkhead wall, etc. The SIV can be minimized by limiting the longitudinal travel distance between an occupant and an interior fixture, because SIV increases with distance traveled.

The curves in Figure 2 plot the relative velocity of an occupant in free-flight against its relative displacement with respect to the car body. The dashed line represents an occupant in the leading cab car of the CEM train-to-train test. The solid line represents an occupant during an $8 \mathrm{G}$ sled test. For both curves, the relative velocity increases with distance traveled, until the occupant impacts part of the interior. The relative velocity is estimated by locating the relative displacement on the curve that is associated with a given seating configuration. The SIV can be minimized by judiciously positioning seats, tables, and bulkheads to arrest the occupant before large relative velocities are attained, or by positioning seats to face opposite the direction of travel, especially in cars that are positioned at an end of the train.

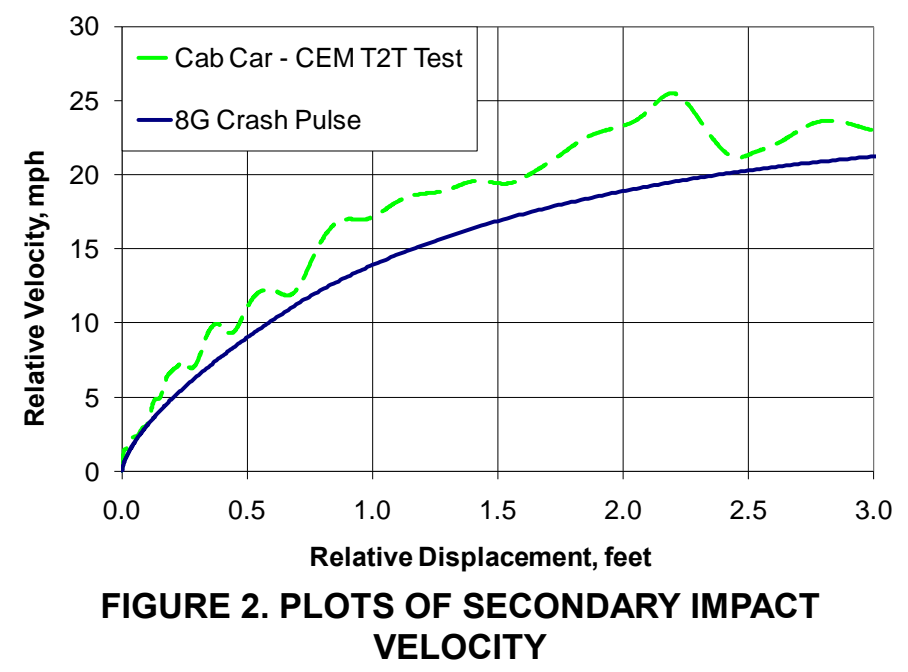

\section{TEST OBJECTIVES}

There are several objectives that must be met to demonstrate that a workstation table is designed with a minimum level of crashworthiness. The table and any components must remain attached to the test fixture when struck by ATDs under collision conditions. The ATDs must remain compartmentalized between the initially occupied seat and the table. Loads to the critical body parts, i.e., head, neck, chest, abdomen, and femur, must be below maximum tolerance levels based on NHTSA research and regulations [11].

An industry safety standard that addresses crashworthiness for passenger rail seats was initially issued by the American Public Transportation Association (APTA) in 1999. Compliance with this seat standard has been required for over ten years. It can be used as a guideline for developing a crashworthiness standard for tables. Seats and tables are similar in that they are both fixtures in the interior of a car. They are the interior objects most likely to be impacted during a train accident. The objectives for seat testing are nearly identical to those for table testing. The only difference is that the abdomen is not a considered a critical body part in evaluating seat crashworthiness.

Seat crashworthiness is assessed primarily via the dynamic sled test prescribed in the industry seat standard. The sled testing is conducted using an 8G, 250 millisecond crash pulse in the shape of an isosceles triangle with a height of $8 \mathrm{G}$ and a base of 250 milliseconds. Two rows of passenger seats are fastened to a test sled as they would be mounted in a passenger rail car. Instrumented ATDs are placed in each seat position.

Standard HIII $50^{\text {th }}$ percentile male ATDs are used to evaluate the above objectives for seat compliance. There is a high degree of fidelity with an actual accident. The seat is loaded by a biofidelic ATD which has no restrictions on motion besides the physical constraints of the seats, table, and floor, which are present in an actual rail vehicle. The ATD is instrumented to measure the forces and accelerations for the critical body parts that are most affected by seat impacts.

Unfortunately, ATD impacts with workstation tables directly load parts of the ATD that are not normally instrumented, such as the abdomen, and therefore cannot be measured with the HIII ATD. To remove this deficiency, the automotive industry has developed the THOR ATD, with an instrumented abdomen capable of measuring abdominal loads in the vicinity of a table impact. For example, the THOR can be used to measure and calculate the abdominal compression ratio and the abdominal viscous criterion.

A standard to evaluate table crashworthiness should include a dynamic sled test with instrumented HIII ATDs, since such a test is capable of assessing nearly all of the objectives defined above. The challenge is to identify additional parameters that can be used to assess the severity of abdominal/thoracic injury caused by table impacts without using a THOR ATD.

Computer models of the prototype table and THOR ATDs using the MAthmatical DYnamic MOdeling (MADYMO) software program [12] have been calibrated and validated against quasi-static and dynamic tests. These models have been used to conduct parametric analyses correlating abdominal/thoracic injury with other measurable table parameters that can be used to evaluate table crashworthiness. 
The results of this modeling, which are described in the companion paper [8], indicate that kinetic energy absorbed by the table provides a meaningful correlation with abdominal injury. Generally, abdominal injury indices decrease as energy absorbed via table crush increases, provided that the peak contact force between the ATD and the table is limited.

A number of different tests have been explored to assess table crashworthiness. The following sections will survey the information gathered during this testing. The test measurements and results will be described, along with the pros and cons of each method in terms of measuring energy absorbed via table crush and peak contact force.

\section{QUASI-STATIC TESTING}

Several quasi-static tests have been performed on the FRA prototype table to characterize its force-crush behavior. Preliminary analysis and quasi-static testing led to design modifications to increase confidence that the table design would perform as desired during the more complicated and expensive full-scale train-to-train test with the THOR ATD. After the fullscale tests indicated that the table met the test objectives, another quasi-static test was conducted to verify the force-crush behavior of the final design. The test conditions, test measurements, and test results are described below.

\section{Test Conditions}

The workstation table was fastened to a rigid test fixture using the same attachment mechanism planned for rail service. The table was destructively tested under a quasi-static loading condition in which longitudinal, loads were applied simultaneously to the table at both seat positions, to evaluate the crashworthiness of the table at each seat position under combined loading.

The loads were applied to the table by two hydraulic cylinders, which were attached to rigid body blocks 15 in wide by 8 in high, approximating the size of a human torso. The vertical sides had a radius of three in. The body blocks were aligned laterally at the center of each seat position and centered vertically on the table edge. The displacement rate of the cylinders was approximately $1 \mathrm{in} /$ minute.

\section{Test Measurements}

The force-time history and displacement-time history of the independent loading rams were measured. The longitudinal displacement of the table top was measured on the side opposite the load applications, in line with the applied loads, using a string potentiometer. To assess encroachment, table penetration into the passenger space on the opposite side of the table was calculated by subtracting the longitudinal displacement of the table (measured by string potentiometers) from the initial longitudinal distance between the table edge and the seat back.

Three-axis reaction loads were also measured at the attachment points between the table and the test sled via three load cells, two at the wall mount and one under the support leg at the floor mount. Still photographs of the table were taken pre- and post-test. The progress of the test was also documented using a digital video camera at two locations (top and side views). A pre-test photo of the quasi-static test set-up is shown below in Figure 3.

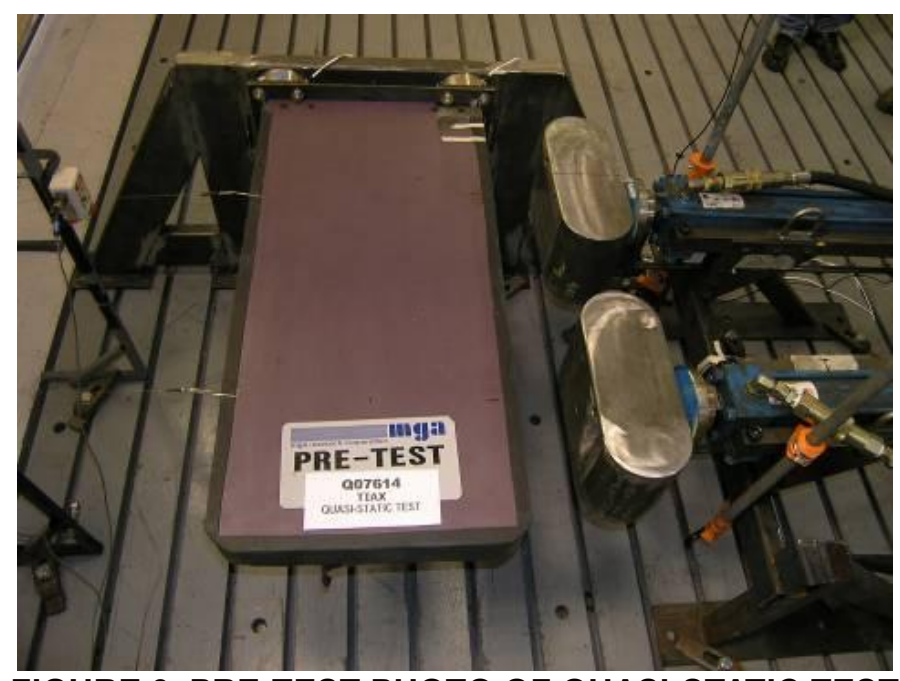

FIGURE 3. PRE-TEST PHOTO OF QUASI-STATIC TEST

\section{Test Results}

The loading rams were deployed nearly 8 in during the test. The wall-side ram was stopped after 7 in of ram displacement because the honeycomb was fully crushed and the load in the steel frame was increasing rapidly. The aisle-side ram was allowed to continue until approximately 8 in of ram displacement, at which point the honeycomb on this side was also exhausted. The difference in peak displacement of the two rams is due to the elastic bending of the center I-beam of the table.

A post-test photo of the table crush is shown in Figure 4, depicting the permanent table crush on the wall-side (top of photo) and aisle-side (bottom of photo).

The force-crush plots for the aisle-side and the wall-side load applications are shown in Figure 5. The force is that measured in the loading ram at each table position. The crush is the displacement of each loading ram, which were actuated to displace together.

When the rams had displaced about 0.3 in and the applied load reached approximately 1,300 lbf, the honeycomb began to crush plastically. The load then gradually increased to about 2,200 lbf and then began to increase rapidly as the honeycomb consolidated. The measured load for the wall-side loading ram eventually reached $4,800 \mathrm{lbf}$ at a displacement of $7 \mathrm{in}$. The measured load for the aisle-side loading ram reached 4,200 lbf at a displacement of 8 in. 

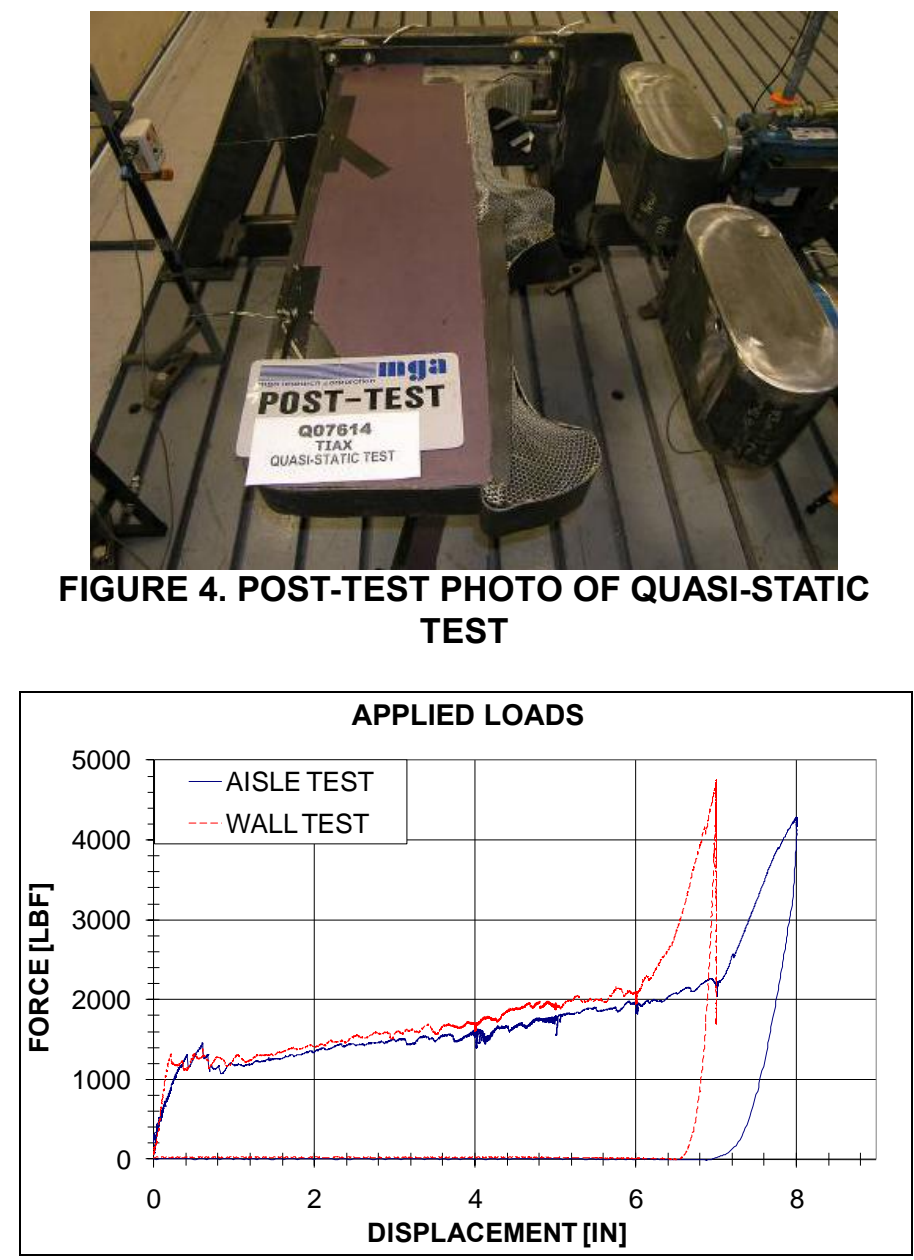

FIGURE 5. TABLE FORCE-CRUSH PLOTS

The largest reaction loads were measured at the wall load cells in the lateral direction. The loads at the two wall-mounted load cells were approximately equal and opposite, with the load cell on the applied load side of the table in tension and the other in compression. The peak load was about 8,000 lbf in tension. The sum of the longitudinal reaction loads measured at the three load cells reached about 7,000 lbf. The peak vertical reaction load was about $430 \mathrm{lbf}$ measured at the attachment of the support leg to the floor.

The energy absorbed by table crush at each table position was calculated by integrating the force vs. displacement plot for each ram from $t_{0}$ to $t_{f}$, where $t_{0}$ is the time that the ram contacts the table, and $t_{\mathrm{f}}$ is the time that the force returns to zero.

The energy absorption plots for each ram as a function of ram displacement are shown in Figure 6. The energy absorbed on the wall-side and aisle-side of the table was approximately 12,000 in-lbf and 14,000 in-lbf, respectively.

The quasi-static test has a number of advantages. It is a relatively inexpensive test. It is also easy to measure the force and displacement time histories and to calculate energy absorbed. The force required to initiate crush, which was a design parameter, is easy to identify. The maximum force allowed can be tied to abdominal tolerance.

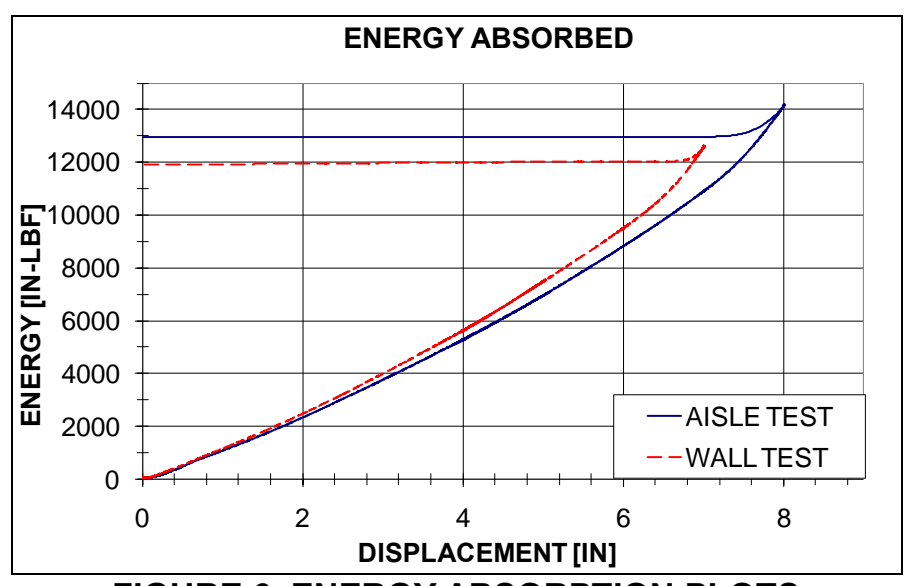

FIGURE 6. ENERGY ABSORPTION PLOTS

A disadvantage of the quasi-static test is that it is not dynamic like a rail accident, and doesn't account for any strain rate sensitivities or other dynamic effects, which may or may not exist in a particular table design.

\section{DYNAMIC PENDULUM TESTING}

Two separate dynamic pendulum tests were performed on the FRA prototype table to characterize its force-crush behavior under dynamic loading conditions. The test conditions, test measurements, and test results are described below.

\section{Test Conditions}

The conditions for the first test were chosen to approximate the energy associated with the earlier THOR table experiment onboard the full-scale CEM train-to-train test in order to correlate the results of the THOR test with the dynamic pendulum test. The mass of the THOR ATD was $170 \mathrm{lbm}$. The velocity at the time of impact with the table was about $12 \mathrm{mph}$. The energy associated with these conditions was approximately 10,000 in-lbf. These initial conditions were therefore used for the first pendulum test.

The conditions for the second pendulum test were chosen to approximate the conditions associated with a standard HIII $50^{\text {th }}$ percentile ATD subjected to an $8 \mathrm{G}$ crash pulse. These conditions are also specified in the APTA seat standard. The impact velocity for an ATD under these test conditions is approximately $9-10 \mathrm{mph}$, resulting in a kinetic energy of about 6,000 in-lbf.

During the period between the first and second pendulum tests, lumped-parameter modeling using MADYMO was conducted to correlate collision conditions between an event defined by an acceleration time history and an event defined by an initial mass and velocity. In order to match the energy absorbed by the table in the two cases, the mass of the pendulum was decreased to $75 \mathrm{lbm}$ for the second test.

Each mass was suspended from the ceiling of the test bay by a set of eight cables that were attached to the pendulum shuttle, four attached to the front of the shuttle, and four attached near the back. The outside cables were suspended at 
an angle of about 30 degrees to provide lateral stability. The inside cables were suspended vertically (i.e., not at an angle like the outside cables) so that the cables did not interfere with one another during the drop. The same rigid body blocks from the quasi-static tests were attached to the leading end of the pendulum shuttle. The freely swinging pendulums were raised to a predetermined height to achieve the required impact velocity, and then released simultaneously. A pre-test photo of the test set-up is shown in Figure 7 (note that the opposite side of the table had been crushed during a previous test).

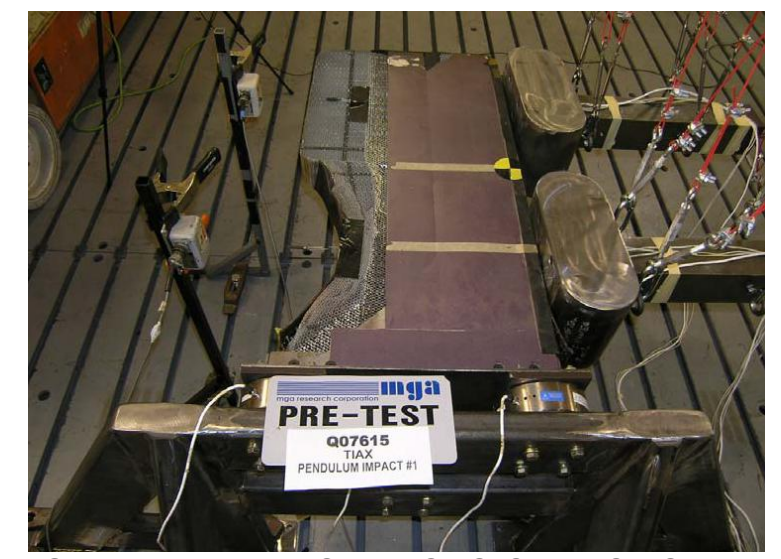

FIGURE 7. PRE-TEST PHOTO OF TEST SET-UP

\section{Test Measurements}

The time- history of the force between the pendulum and the table was measured by a uniaxial load cell placed behind the impact face of the hollow, rigid body block. The acceleration time history of each pendulum was measured by a three-axis accelerometer mounted to the top of the shuttle. The reaction loads at the table attachment points were measured with threeaxis load cells, as per the quasi-static test set-up. The longitudinal displacement time history on the table side opposite each impact mass was measured with string potentiometers. Still photographs of the table were taken preand post-test. The progress of the test was also documented using a high-speed digital video camera at two locations (top and side views).

\section{Test Results}

In the first pendulum test, which had a kinetic energy of about 10,000 in-lbf, the impact of the pendulums produced about 5 in of permanent deformation on both the wall-side and aisle-side of the table (see post-test photo in Figure 8). The crush on the wall-side of the table was slightly greater than on the aisle side due to the increased rigidity associated with the proximity to the wall mount. The cantilevered aisle-side experienced more elastic deformation of the center I-beam.

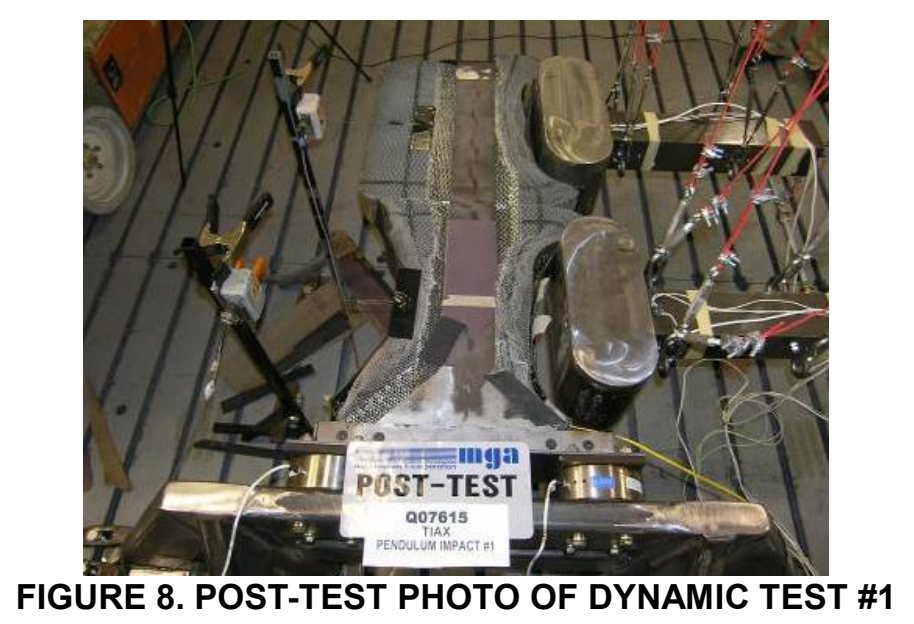

The force time history plots measured from the load cells on the pendulum masses are shown in Figure 9. After the initial dynamic spike, the forces plateau to a relatively constant force level of 1,000 lbf to $1,500 \mathrm{lbf}$ while the honeycomb crushes. These force levels are similar to the average crush force of the honeycomb during the quasi-static test, indicating that there is not a significant strain-rate sensitivity in this table design under these dynamic loading conditions. The honeycomb was not quite fully crushed under these loading conditions.

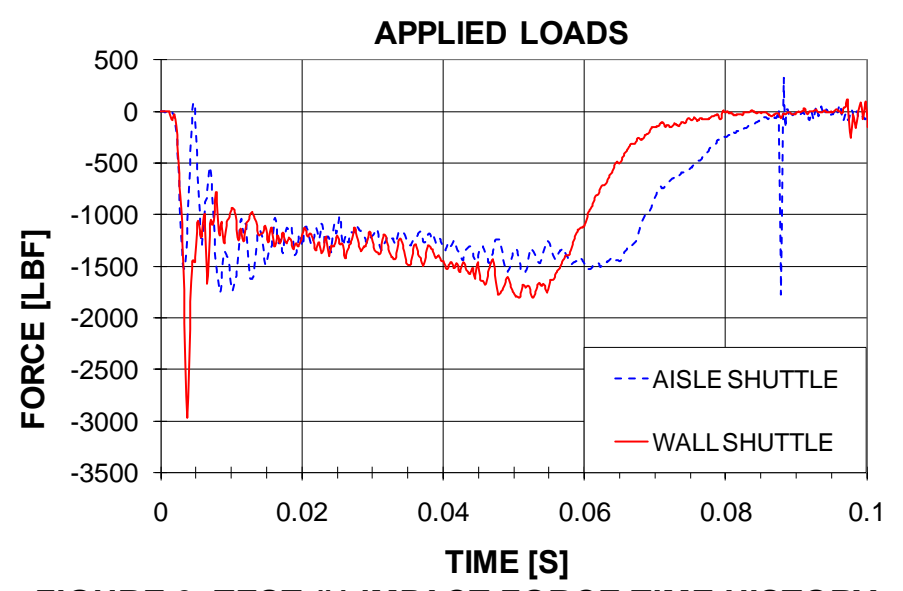

FIGURE 9. TEST \#1 IMPACT FORCE TIME HISTORY

In the second pendulum test, which had a kinetic energy of about 6,000 in-lbf and a mass of $75 \mathrm{lbm}$, the table crush measured after the test was only 1.5 to 2.5 in on both sides of the table (see post-test photo in Figure 10). The crush on the wall-side of the table (left, bottom side in photo) was somewhat less than the aisle-side (right, bottom side in photo) because the rigid body block grazed the steel support structure, which dissipated some kinetic energy. As expected, the crush was significantly less than in the first pendulum test because the kinetic energy was reduced by $40 \%$. 


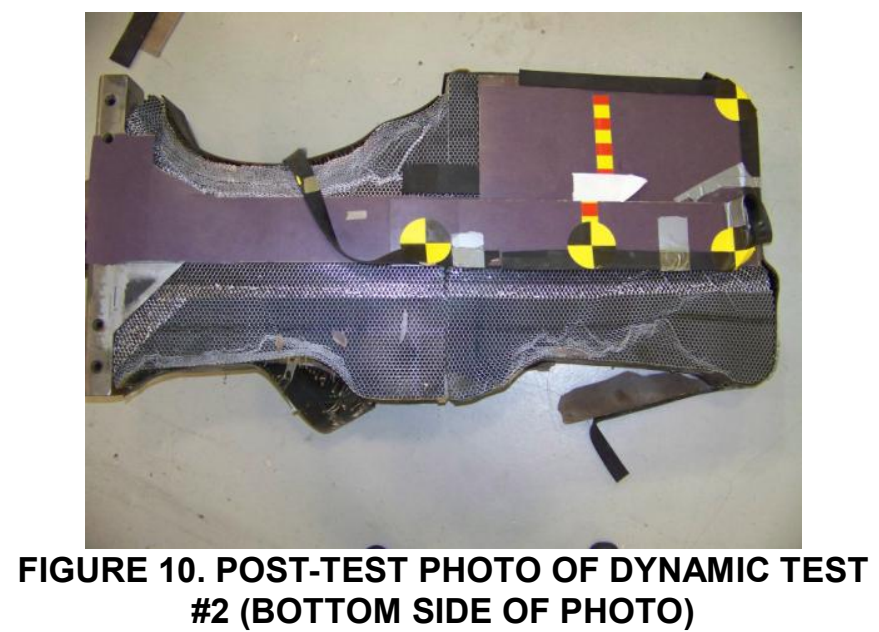

The force time history plots measured from the load cells on the pendulum masses are shown in Figure 11. The initial dynamic spike was less significant in this test and the oscillation in the force was greater due to the lighter masses. The average force due to the aisle-side mass impact was generally between 1,000 $\mathrm{lbf}$ and 1,700 lbf. The average force range due to the wall-side mass was much greater because it struck the steel support structure near the wall mount.

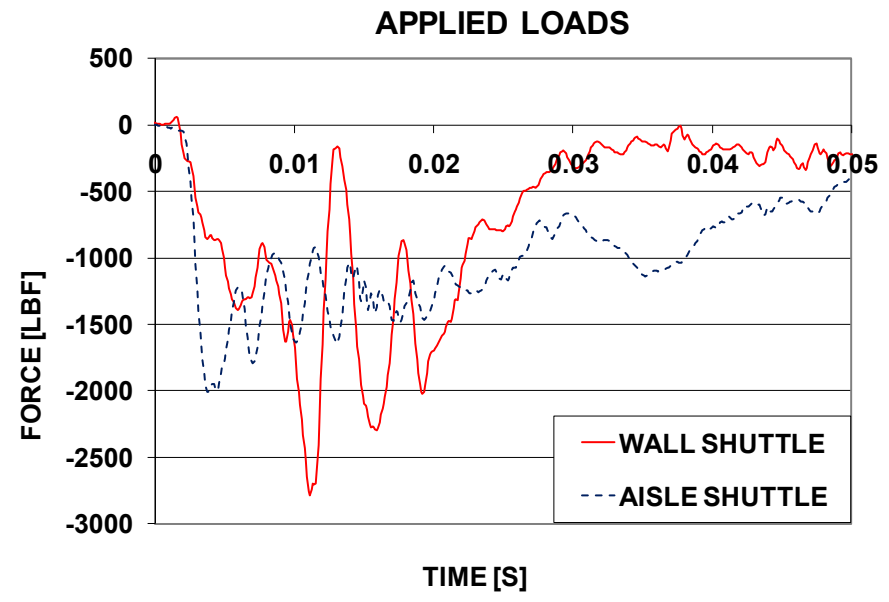

FIGURE 11. TEST \#2 IMPACT FORCE TIME HISTORY

The dynamic pendulum tests were performed to determine their suitability for evaluating energy absorption, force levels during crushing, and peak accelerations to correlate with injury indices. Ideally, the pendulum tests would have provided a useful comparison to ATD impacts because the test was dynamic, as are rail vehicle accidents. However, there were several disadvantages to this test method.

It was desirable to allow as many degrees of freedom as reasonable to assess occupant compartmentalization; however the freedom of motion made it difficult to precisely control the point of impact. Although the effective mass of a HIII $50^{\text {th }}$ percentile ATD was found to be $75 \mathrm{lbm}$ via MADYMO modeling, the lower mass caused more oscillation and noise in the data signals. There were also complications associated with correlating the results from an initial velocity test condition with results from an ATD subjected to a prescribed acceleration time history. Additionally, the pendulum test cannot assess ATD kinematics or injury indices.

\section{DYNAMIC DROP TOWER TESTING}

Drop tower testing is similar to pendulum testing, but it is simplified to allow only one degree of freedom. With proper instrumentation, drop tower testing can be used to evaluate table crashworthiness under dynamic loading conditions in terms of energy absorption behavior of the table, and peak and average forces generated by the mass impact. The test conditions and test measurements are described below. Selected results from drop tower testing conducted by students on a table designed by students at California Polytechnic State University at San Luis Obispo are also presented.

\section{Test Conditions}

As in pendulum testing, the table can be fastened to a test fixture as it would be mounted in rail service. The table would be rotated 90 degrees to perpendicular so that the masses would drop onto the edge of the table top. The rigid blocks representing a human torso (described above) would be secured to additional mass that is equivalent to the mass of an HIII $50^{\text {th }}$ percentile ATD. The impact masses would be centered at each seat position. The drop height would be calculated to achieve the desired kinetic energy upon impact. The masses would be released at exactly the same time, but would fall independently once released.

\section{Test Measurements}

The test set-up would include instrumentation to measure the acceleration-time history of each mass. A load cell would be placed in front of the impact mass to measure the impact load. The filtered acceleration time histories could be multiplied by the masses to estimate the force time history. If there was good correlation between these two results, it would increase the confidence in the accelerometer data, such that it could be integrated to estimate velocity and displacement of the masses. The integrated velocity and displacement data could be compared to the estimated impact velocity and initial drop height to verify the accuracy of the data. String potentiometers could also be used to measure displacement of both the leading and aft edges of the table top, which could be used to calculate table crush and bending. These results could be used to evaluate energy absorbed by table crush and average and peak table forces.

The force time history plots shown in Figure 12 correspond to the acceleration time history data multiplied by the impact mass of $170 \mathrm{lbm}$ for each mass during the drop tower test conducted by students at Cal Poly. There is an initial dynamic spike, but the average force after the spike is relatively constant at around 1,000 lbf. The Cal Poly drop tower testing did not include additional instrumentation to directly measure force or displacement during the test so energy absorbed by table crush cannot accurately be calculated. 


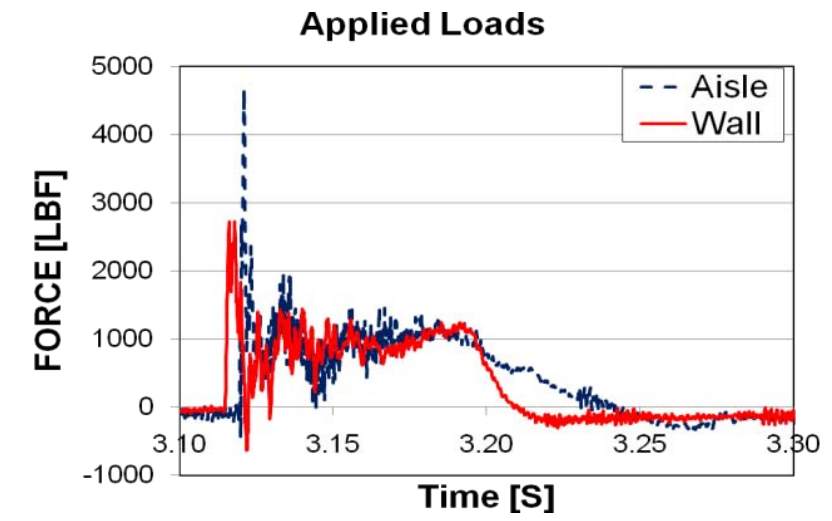

FIGURE 12. FORCE TIME HISTORY FOR CAL POLY TABLE

A drop tower test is a dynamic event and it is easy to precisely control the impact, but it still has many of the same issues as pendulum testing related to equivalent mass, energy correlation, ATD kinematics and injury indices. There are additional issues associated with energy loss due to friction between the dropped masses and the guideposts and accurately measuring the impact velocity and associated kinetic energy.

\section{SUGGESTED TEST REQUIREMENTS}

Based on the above survey of several testing methods, and in conjunction with results from testing and MADYMO modeling with a THOR ATD, the following two tests, with associated test conditions, measurements, and performance requirements, are proposed for an industry table safety standard.

\section{Test \#1 - Dynamic Sled Test with HIII $50^{\text {th }}$ Percentile ATD}

This proposed test would be nearly identical to the sled testing specified in the APTA seat standard, with the addition of a workstation table. Some modifications are made to the injury measurements and performance requirements.

\section{Test Conditions}

A passenger seat (single, double, triple, etc. to represent the intended service conditions) would be fastened to the test sled at the nominal location relative to the table for the intended rail service. A facing seat on the opposite side of the table would be optional. A workstation table would be fastened to the test sled as it would be mounted to a rail car. Instrumented HIII $50^{\text {th }}$ percentile ATDs would be placed, one in each seat position, facing the direction of travel. The test fixture would act as a rigid mounting point for the table and seats.

The test sled would be subjected to an $8 \mathrm{G}, 250$ millisecond crash pulse in the shape of an isosceles triangle.

\section{Test Measurements}

The test measurements would be similar to those measured in the APTA seat standard, with the addition of chest deflection. Below is a list of suggested test measurements:
- Triaxial head acceleration-time history for each ATD

- Triaxial chest acceleration-time history for each ATD

- Axial left and right femur force-time history for each ATD

- Upper neck extension/flexion bending moment, My, for each ATD

- Upper neck axial force, Fz, for each ATD

- Upper neck shear force, Fx, for each ATD

- Chest deflection, measured at sternum, for each ATD

- Longitudinal acceleration-time history of the test sled

The longitudinal distance from the forward-most location on the table to the front of the facing seat back (or theoretical position if a facing seat is not used) would be measured posttest to evaluate entrapment due to table displacement on the far edge of the table:

The following injury criteria would be computed in accordance with 49 CFR 571.208 [11]:

- HIC15

- $3 \mathrm{~ms}$ chest Gs

- Axial femur load

- Peak upper neck axial tension/compression forces

- Nij

- Chest deflection, measured at the sternum

Still photographs of the table would be taken pre- and posttest. The progress of the test would be documented using a high-speed digital video camera at two locations (overhead and side views).

The performance requirements would include ATD compartmentalization, positive table attachment, and injury indices requirements per those in the APTA seat standard, with an additional requirement for chest deflection, chest viscous criterion, and a different IARV for the chest deceleration criteria.

Chest deflection was originally used in the automotive industry to assess direct impact between an automobile steering column and an ATD's chest. The sensor for chest deflection is located behind the ATD's sternum, which is generally located near the point of impact with a steering column, but not with a workstation table. The measurement would provide additional information related to the table impact, particularly if the table engages part of the rib cage. A stricter requirement will be specified for table testing than for automotive testing since chest compression in table testing will be referred from an impact not directly in line with the sensor, whereas the chest deflection sensor is generally in line with the steering column in automotive testing.

\section{Performance Requirements}

For a successful test, the following requirements must be met: 
- The table and any table components must remain attached to the test fixture or simulated rail car structure.

- The crush of the table edge shall not result in any exposed sharp edges or spaces capable of entrapping an occupant during a rail accident.

- During and after the test, the table shall not penetrate the survival space reserved for occupants in the facing seat, where applicable, so as not to entrap the facing passengers or prevent egress. The survival space shall not be less than 15 inches, as measured in the horizontal plane from the forward-most location on the table to the front of the facing seat back.

- The ATDs shall be compartmentalized between the initially occupied seat and the table.

- All injury measurements must meet the following injury criteria in Table 2, most of which are the same as those defined in CFR 49 Part 571, Standard No. 208: Occupant Crash Protection [11]. The chest deceleration and deflection criteria are more restrictive than the automotive standard to compensate for the fact that the contact between the ATD and the table is not in line with the chest sensors.

TABLE 2. INJURY CRITERIA REQUIREMENTS

\begin{tabular}{|l|c|}
\hline \multicolumn{1}{|c|}{ Criteria } & $\begin{array}{c}\text { Injury } \\
\text { Threshold }\end{array}$ \\
\hline HIC15 & 700 \\
\hline Nij & 1.0 \\
\hline Neck Axial Tension (Fz) & $\begin{array}{c}+937 /-899 \mathrm{lbf} \\
(4,170 / 4,000 \mathrm{~N})\end{array}$ \\
\hline Chest deceleration over 3 ms clip, Gs & 32.5 \\
\hline Chest deflection & $\begin{array}{c}2.2 \mathrm{inches} \\
(55 \mathrm{~mm})\end{array}$ \\
\hline Chest Viscous Criterion & $\begin{array}{c}2.6 \mathrm{ft} / \mathrm{s} \\
(0.8 \mathrm{~m} / \mathrm{s})\end{array}$ \\
\hline Femur Load & $\begin{array}{c}2,250 \mathrm{lbf} \\
(10,000 \mathrm{~N})\end{array}$ \\
\hline
\end{tabular}

The sled test with an HIII $50^{\text {th }}$ percentile ATD has the benefit of being a dynamic event with a high degree of fidelity to represent the occupant kinematic, compartmentalization, table attachment, and injury assessment for the head, chest, neck, and femur. The only disadvantage is that the HIII ATD cannot measure loads delivered directly to the abdomen. The following test is recommended to assess abdominal injury.

\section{Test \#2 - Quasi-Static Test}

A quasi-static test is proposed to measure the energy absorbed by table crush without exceeding a peak force limit, which is associated with abdominal tolerance levels.

\section{Test Conditions}

A workstation table would be mounted to a rigid test fixture or simulated car structure using the same fasteners or attachment mechanism used in service, i.e., bolts, screws, track, tapping plate, etc. The table would be destructively tested under quasi-static loading conditions. A series of tests would be performed in which a quasi-static load is applied to the table at each seat position, to evaluate the crashworthiness of the table at each seat position.

The load would be applied to the table via a rigid block (depicted in Figure 13) to which the hydraulic cylinder would be attached. The block would be aligned laterally at the center of each seat position for the intended service. The blocks would be centered vertically on the table edge. The displacement rate of the cylinder would be approximately one in/minute. The test would proceed until the applied load reached 2,250 lbf, then the ram would be retracted to remove the applied lo

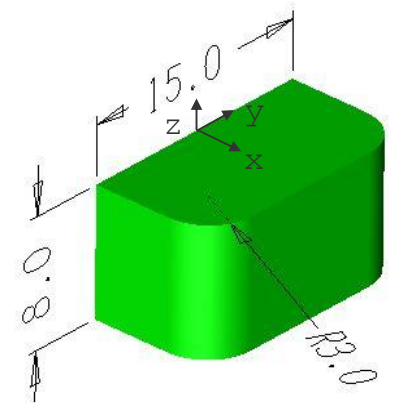

\section{FIGURE 13. LOADING BLOCK (DIMENSIONS ARE IN INCHES)}

\section{Test Measurements}

The force-time history and displacement-time history of the loading ram would be measured in accordance with SAE J211-1 [13]. The longitudinal displacement of the table top would be measured on the side opposite the load application in line with the applied load using a string potentiometer.

The table penetration into the passenger space on the opposite side of the table would be calculated by subtracting the longitudinal displacement of the table (measured by a string potentiometer) from the initial theoretical longitudinal distance between the table edge and the seat back.

The energy absorbed by plastic (permanent) table crush at each table position would be calculated as follows:

- Plot the applied load vs. displacement of the loading ram

- Integrate the load vs. displacement plot until the applied load returns to zero, thus subtracting the elastic energy stored in the table.

Still photographs of the table would be taken pre- and post-test. The progress of the test would also be documented using a digital video camera at two locations (top and side views). 


\section{Performance Requirements}

For a successful test, the following requirements must be met:

- The table and any table components must remain attached to the test fixture.

- The crush of the table edge must minimize any sharp edges or points of entrapment which might endanger an occupant.

- During and after crushing of the table, a minimum of 15 in of survivable space must be preserved for facing occupants, based on the predominant seat pitch used for seats surrounding tables.

- The energy absorbed by the plastic (permanent) table crush, as calculated above, must be at least $6,200 \mathrm{in}-\mathrm{lbf}$ without the force exceeding 2,250 lbf.

\section{CONCLUSIONS}

After evaluating the benefits of several testing techniques, dynamic sled testing with an HIII $50^{\text {th }}$ percentile ATD and quasi-static testing have been proposed to assess compliance with the recommended test objectives. The combination of these two tests can be used to evaluate table attachment, occupant compartmentalization, table encroachment on facing passengers, and injury to critical body parts, including head, neck, chest, abdomen, and femurs. The dynamic sled test can be used to evaluate all of these objectives except for abdominal injury. The quasi-static test can be used to assess the energy absorption capacity of the table without exceeding a defined force limit, which is tied to abdominal injury tolerance levels. The test conditions, test measurements, and performance requirements have been defined for each test. The rationale behind the specific performance requirements for each set of test requirements are explained in detail in the previously mentioned companion paper [8]. These test and performance requirements have been proposed in a draft industry table standard. The requirements in these two tests are expected to significantly improve the collision safety associated with workstation tables.

\section{ACKNOWLEDGMENTS}

This work was performed as part of the Equipment Safety Research Program sponsored by the FRA's Office of Research and Development. The authors would like to thank Eloy Martinez, Program Manager, and Kevin Kessler, Division Chief, Equipment and Operating Practices Research Division, Office of Research and Development, Federal Railroad Administration, for their support. Additional thanks go to David Tyrell, Program Manager at the Volpe Center, for technical direction, and Ritch Hollingsworth, advisor to Cal Poly students, for permission to publish the drop tower test data.

\section{REFERENCES}

[1] National Transportation Safety Board, "Collision of Burlington Northern Santa Fe Freight Train With Metrolink Passenger Train, Placentia, California, April 23, 2002," Railroad Accident Report NTSB/RAR-03-04, adopted on 10/7/2003.

[2] National Transportation Safety Board, "Collision of Amtrak Train No. 88 with Rountree Transport and Rigging, Inc., Vehicle on CSX Transportation, Inc., Railroad Near Intercession City, Florida, November 30, 1993," Railroad Accident Report NTSB/HAR-95/01, adopted on 5/16/1995.

[3] National Transportation Safety Board, "Collision Between Metrolink Train 210 and Ford Crew Cab, Stake Bed Truck at Highway-Rail Grade Crossing, Burbank, California, January 6, 2003," Highway Accident Report NTSB/HAR-03/04, adopted on $12 / 2 / 2003$.

[4] Haffner, M., et al., "Foundations and Elements of the NHTSA THOR Alpha ATD Design," paper 458, presented at the 17th International Technical Conference on the Enhanced Safety of Vehicles, Amsterdam, Holland.

[5] Parent, D., Tyrell, D., Perlman, A.B., "Evaluating Abdominal Injury in Workstation Table Impacts," Compendium of Papers, 84th Annual Meeting, Transportation Research Board, January 2005.

[6] Severson, K., Parent, D., "Train-to-Train Impact Test of Crash Energy Management Passenger Rail Equipment: Occupant Experiments," American Society of Mechanical Engineers, Paper No. IMECE2006-14420, November 2006.

[7] APTA SS-C\&S-016-99, Standard for Row-to-Row Seating in Commuter Rail Cars, The American Public Transportation Association, Washington, DC.

[8] Muhlanger, M., Parent, D., Severson, K., and Perlman, B., "Development of Performance Requirements for a Rail Passenger Workstation Table Safety Standard" American Society of Mechanical Engineers, Paper No. RTDF2010-42031, October 2010.

[9] Parent, D., Tyrell, D., Perlman, A.B., "Crashworthiness Analysis of the Placentia, CA Rail Collision," Proceedings of ICrash 2004, International Crashworthiness Conference, San Francisco, California, July 14-16, 2004.

[10] Parent, D., Tyrell, D., Rancatore, R., Perlman, A.B., "Design of a Workstation Table with Improved Crashworthiness Performance," American Society of Mechanical Engineers, Paper No. IMECE2005-82779, November 2005.

[11] Code of Federal Regulations, Title 49, Part 571, Section 208, Occupant Crash Protection, October 1, 2002.

[12] MADYMO, Version 7.0, TNO Automotive, Delft, The Netherlands.

[13] SAE J211-1, Surface Vehicle Recommended Practice, March 1995. 